\title{
Conceptual sizing of next supersonic passenger aircraft from regression of the limited existing designs
}

\author{
Keith F. Joiner ${ }^{1}$, Jordan Zahra ${ }^{1}$ and Obaid Rehman ${ }^{1}$ \\ ${ }^{1}$ School of Engineering and Information Technology, University of New South Wales (NSW), Australian Defence Force Academy, Canberra, \\ 2600, Australia
}

\begin{abstract}
Despite previous versions, there are no current supersonic passenger transport aircraft. Much aircraft research is focused on hypersonic flight and the new technologies therein and is therefore unlikely to add to commercial versions anytime soon. This study re-examines conceptual sizing of a supersonic transport aircraft based on extant supersonic designs in order to ignite research into whether a commercially-viable design might exist. Key metrics are developed using distances between likely airport network nodes, an assumed number of passengers, and a reduction in transport time to one-third of current journeys. The study uses multiple response regression of known designs to develop key performance formulae, which are then optimized to set performance values so as to estimate an initial aircraft size, including an expected value analysis to guide the next conceptual design iteration. Twenty years ago a NASA Langley Research optimization system was used to examine non-linear regression of supersonic aircraft designs and to optimize such a design around similar performance criteria. In contrast, this work is the first supersonic transport aircraft sizing to use commercially-available Excel add-on software and standard design-for-sixsigma analysis techniques; notably for the sensitivity analyses to guide the next design iteration.
\end{abstract}

\section{Nomenclature}

$\begin{array}{lll}b= & \text { aircraft wing span }(\mathrm{ft}) \\ h= & & \text { aircraft height }(\mathrm{ft}) \\ l= & \text { aircraft length }(\mathrm{ft}) \\ L / D= & \text { lift to drag ratio } \\ M T O W= & \text { maximum take-off weight }(\mathrm{lb}) \\ S= & & \text { aircraft wing area (sq ft) } \\ T / W= & \text { thrust to weight ratio } \\ W_{E}= & \text { empty weight }(\mathrm{lb}) \\ W / S= & \text { wing loading }(\mathrm{lb} / \mathrm{sq} \mathrm{ft})\end{array}$

\section{Introduction}

Current airliner technology features large-capacity, turbine-powered aircraft travelling at subsonic speeds in order to travel relatively large distances as quickly as these aircraft can. There have been supersonic aircraft such as the Concorde and Tupolev TU-144, however since Concorde stopped flying in 2003, all current and planned commercial passenger transport aircraft remain subsonic. Much of the airline design activity is focused on making these subsonic aircraft longer-range to decrease stop-overs, but the future of air transportation needs to commercially re-cross the sonic 'barrier' to substantially get intercontinental aircraft travel times down. Just as very-fast trains have leveraged increasing travel demand to create high-speed network cores in Europe and Japan, the increasing demand for air travel should create the opportunity for a supersonic air transport network.

Much of the major aircraft research is into hypersonic flight and the technological benefits that ensue if this can be achieved. Examples are the European Union's Long-Term Advanced Propulsion Concepts and Technologies (LAPCAT) program [1] and the U.S. military experimental aircraft like the X-51 [2]. Such hypersonic research aircraft use advances in technology that are unlikely to achieve commercially-viable designs for the airline industry for many decades.

What is more likely to realize reduced intercontinental airline times in the short-term is if some aircraft research is devoted to revisiting supersonic aircraft design, using proven technologies focused on optimizing commercial viability. Such multidiscipline aircraft design optimization was seminally characterised in 1997 [3] and research at that time using the NASA Langley Research Center [4] sought to minimize the gross take-off weight of a supersonic transport aircraft designed to carry 305 passengers at a cruise speed of Mach 2.4 for a range of 5,000 nautical miles (nm). This optimization research used both non-linear regression and neural network techniques with a great many design criteria, importantly including considerations like the take-off and landing criteria and aircraft engine performance. For relevance to this study, it had a solved aircraft take-off weight of around 666,665 lb and wing size of $8,162 \mathrm{sq} \mathrm{ft}$. At a more graduate level, such a 
supersonic conceptual design would conventionally use the textbook pre-solved regression methods of [5], which involve usually two factors at a time and which is illustrated well for supersonic aircraft in [6].

This study revisits the supersonic transport conceptual design problem and optimizes with a method between the two extremes of the NASA optimization techniques and the Raymer textbook method. The study does so by exploiting new Excel software add-ons available to most graduates and several experimental analysis techniques used in Design For Six Sigma (DFSS) techniques [7]. As such, this research exploits improved probabilistic modelling and optimization packages to perform a high-level initial aircraft sizing based on prior design data. Use of DFSS methods for robust optimization was first reviewed extensively in [8] and formally this study is the first possible iteration in the process of 'Identify, Design, Optimize and Validate' as described and exemplified in [9], however in this case applied to aircraft conceptual design. The publication of such examples is hoped will promote wider use of DFSS capabilities outside the U.S. and Europe [10], especially sensitivity analyses in conceptual design.

The analyse packages used in this research were DOE PRO XL ${ }^{\mathrm{TM}}$ and Quantum $\mathrm{XL}^{\mathrm{TM}}$, both of which are Excel add-ons copyrighted by Air Academy Associates, LLC, and SigmaZone.com.

\section{Historical Data Regression Set-up}

The inputs to the study were initially as vast as possible whilst maintaining enough degrees of freedom to analyse interactions between the input parameters. The available degrees of freedom for analysis was constrained by the limited number of candidate aircraft able to be analysed; namely the 16 in Table 1 . Hence a candidate list of different input design parameters was gathered (Table 2) so as to then screen the most important factors. Four different design output parameters were gathered: Maximum Speed, Maximum Mach Number, Service Ceiling, and Range. Note that for variable parameters, such as the wing area of many variable-sweep aircraft or the ability to use afterburners for several aircraft, the parameter with the highest velocity was always taken (i.e., often resulting in wings swept back and wet thrust using afterburners).

A screening analysis was conducted in DOE PRO $\mathrm{XL}^{\mathrm{TM}}$ using the 16 independent supersonic aircraft for 15 input factors but with no statistically significant factors and saturated degrees of freedom. To rectify this problem, a much wider screening study would be needed with more different aircraft, however, there is simply not enough unique examples of supersonic aircraft. Using different variants of the same aircraft would have unfairly skewed the results, while putting multiple military fighter aircraft into the study would not have embodied the high take-off weights needed for comparison against supersonic aircraft concepts. Instead, classical aircraft texts $[5,11]$ were used to inform reducing the analyses to just the eight key factors shown in Figure 1.

\section{Regression Analysis}

The regression analysis used a practical DFSS method [7, pp. 135-150] and ran easily for the effects of the eight first-order input factors. However, the analysis required careful repeat coding within the seven degrees of freedoms to garner any of the 28 possible two-way interactions and eight quadratic terms that could be significant. Also, each of these 44 terms are different for each of the four output parameters. The analysis excluded higher-order interactions such as three-way interactions and cubic terms as there was insufficient degrees of freedom. Insignificant factors were then removed progressively from the regression model based on their level-of-significance. Such refining of factors significant for all output responses is 'inverse screening' [12, p. 224] and is a robust way to simplify. The final model for each output parameter was checked for its adjusted R-squared value, multi-collinearity and overall model significance [7]. Only the multi-collinearity was poor, however, this is frequently the case in historical data analysis. While results were otherwise statistically adequate, a diagnostic residual analysis revealed high leverage and the Cook's D statistic on two runs: namely the X-15 and X-2 aircraft. Both these aircraft are experimental and very short range when compared to the other aircraft, so they were removed and the process repeated with 14 aircraft types and five degrees of freedom.

Table 1 Supersonic Aircraft Designs used

\begin{tabular}{cccc}
\hline Tupolev Tu-160 & XB-70 Valkyrie & B-1B Lancer & Tupolev Tu-144 \\
Concorde & Sukhoi T-4 & Tupolev Tu-22M & Convair B-58 \\
Lockheed SR-71 & BAC TSR-2 & Mikoyan MiG-31 & F-111G Aardvark \\
MiG-25P Foxbat & F-14 Tomcat & X-15 & X-2 Starbuster \\
\hline
\end{tabular}

Table 2. Candidate Input Parameters to Supersonic Aircraft Regression

\begin{tabular}{cccc}
\hline Year Commissioned & Empty Weight $\left(\mathrm{W}_{\mathrm{E}}\right)$ & Loaded Weight & Engine Type \\
Length (l) & Wingspan $(\mathrm{b})$ & Height $(\mathrm{h})$ & Wing Area (S) \\
Wing Type & Wing Loading (W/S) & Number of Engines & Lift to Drag (L/D) Ratio \\
Maximum Take Off & Maximum Engine Thrust & Thrust to Weight (T/W) & \\
Weight (MTOW) & Ratio & \\
\hline
\end{tabular}




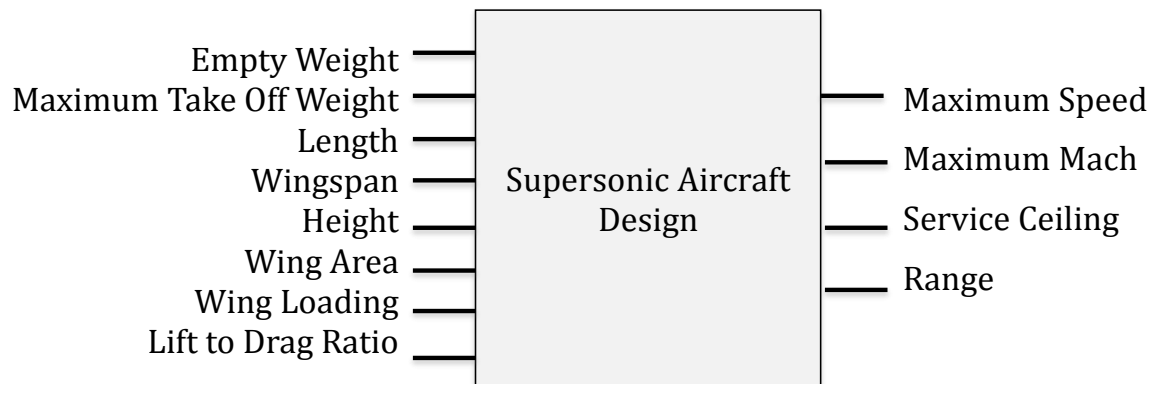

Figure 1. Illustration of final multi-factor inputs ( 8 of) and multi-responses (4 of)

The analysis yielded the regression formulae in equations 1-4 and associated Pareto charts of significant terms. Only the Pareto for maximum speed is given as an example of the process used. The formulae are un-coded and the units are in pounds and feet, while key statistical regression information are in the footnotes. The use of these Pareto charts to visualize effects on each of the output responses aided enormously in the inverse screening as forecast in [12, pp. 225-226].

Maximum Speed (knots) $=-3288.7693-0.01658 \times$ $W_{E}-0.01551 \times$ MTOW $+74.210 \times l+133.665 \times b-$ $122.186 \times h-0.1032 \times S+5.337 \times W / S+192.235 \times$ $L / D+(0.000391 \times$ MTOW $\times h)+(0.00000221 \times$ MTOW $\times$ $S)-(1.0593 \times l \times b)$

The most significant effect on maximum speed from equation (1) and Figure 2 are of course geometrical, leading with the interaction of aircraft length (factor $\mathrm{C}$ ) and wingspan (factor D), shown as interaction CD. Other key factors are wing area, empty and take-off weights and the interactions of take-off weight (factor B) with both wing area (factor F) and with height (factor E) (i.e., BE \& $\mathrm{BF})$.

Maximum Mach $=-5.6143-0.00002914 \times W_{E}-$ $0.0000293 \times$ MTOW $+0.139 \times l+0.2392 \times b-0.2358 \times$ $h-0.0001942 \times S+0.008393 \times W / S+0.2991 \times L / D^{+}$ $(0.000000773 \times$ MTOW $\times h)+(4.151 \times \mathrm{h}-09 \times$ MTOW $\times$ $S)-(0.001991 \times l \times b)$

The most significant effect on maximum Mach Number mirrored maximum speed, since these outputs are closely

\footnotetext{
${ }^{\mathrm{b}}$ R-sq. $=0.9969 ;$ Adj. R-sq. $=0.9797 ; \mathrm{p}<0.0444$ all terms except $M T O W$ at $\mathrm{p}=0.0715$ (likely sig.) and $l, b$ and $h$ all kept due to hierarchy; $\mathrm{F}=58.05$, Sig. $\mathrm{F}=0.0171$; Multi-coll. poor with tol. $<0.23$.

${ }^{\mathrm{c}} \mathrm{R}$-sq. $=0.9992 ;$ Adj. R-sq. $=0.9948 ; \mathrm{p}<0.0253$ all terms except $h$ at $\mathrm{p}=0.0826$ (likely sig.); $\mathrm{F}=228.00$, Sig. $\mathrm{F}=0.0044$; Multi-coll. poor with tol. $<0.24$.
}

linked, being the same both proportionally and in order. The only difference to maximum speed was that more of the lesser terms achieved significance such as $M T O W$ and wingspan.

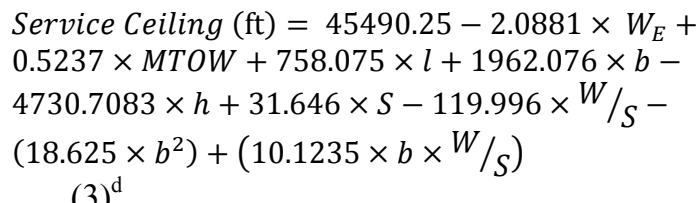

The service ceiling equation was weak: unfortunately, all relationship in this formula collapses if the regression is forced to try to improve by rigorously removing terms with only a likelihood of significance. This weak relationship was persisted with so as to retain some related constraint in this dimension for the optimization. The most significant effect on service ceiling were likely to be empty and take-off weights, followed by wing area.

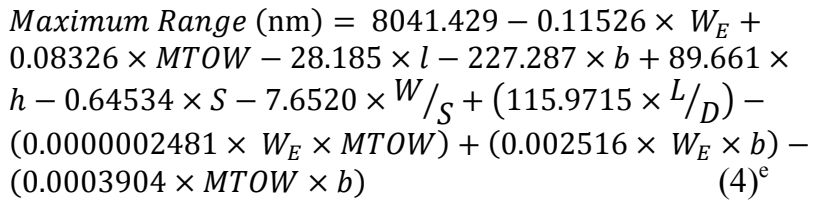

The most significant effects on range were not surprisingly from weight, leading with interactions of empty weight (factor A) with wingspan (factor D) (i.e., $\mathrm{AD}$ ) and with maximum take-off weight (factor B) - the latter (i.e., AB) being a weight squared.

Residual diagnostics of each output response regression revealed a number of aircraft in the analysis

\footnotetext{
${ }^{\mathrm{d}} \mathrm{R}$-sq. $=0.9190 ;$ Adj. R-sq. $=0.6489 ; \mathrm{p}<0.05$ all terms except $W_{E}, S$ and $W / S$ where $\mathrm{p}<0.1$ (likely sig.) and $L / D$ and one interaction are weak sig. $(\mathrm{p}<0.15) ; \mathrm{F}=3.4028$, Sig. $\mathrm{F}=$ 0.1710 ; Multi-coll. poor with tol. $<0.2$.

${ }^{\mathrm{e}}$ R-sq. $=0.9980 ;$ Adj. R-sq. $=0.9912 ; \mathrm{p}<0.0146$ all terms except $W / S$ at $\mathrm{p}=0.0627$ (likely sig.) and $b$ kept due to hierarchy; $\mathrm{F}=147.11$, Sig. $\mathrm{F}=0.0008$; Multi-coll. poor with tol. $<0.1687$.
} 


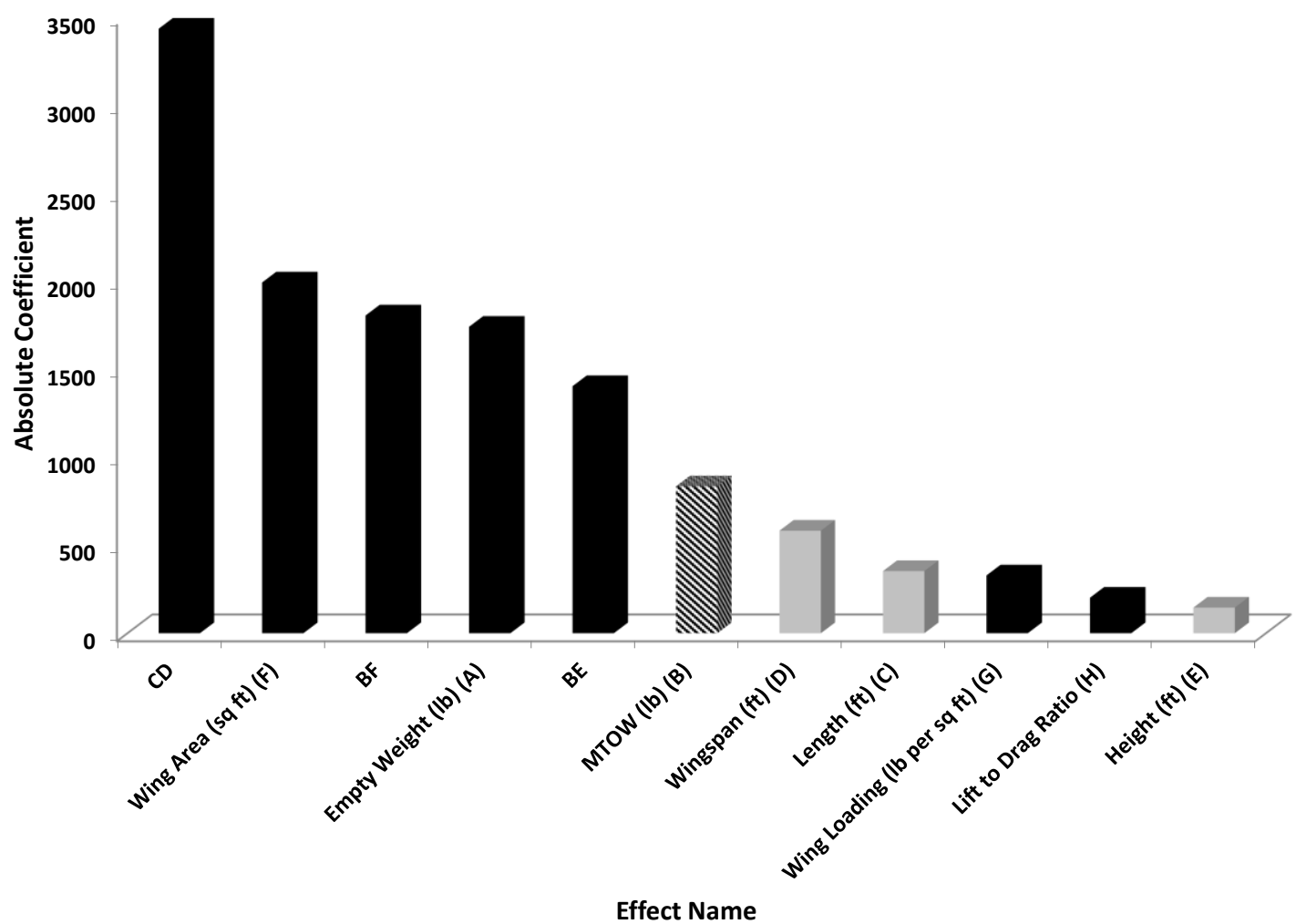

Figure 2. Pareto of Coefficients for Maximum Speed (knots) with black indicating significant ( $<<0.05)$, hatched likely to be significant $(0.05<\mathrm{p}<0.1)$ and grey non-significant

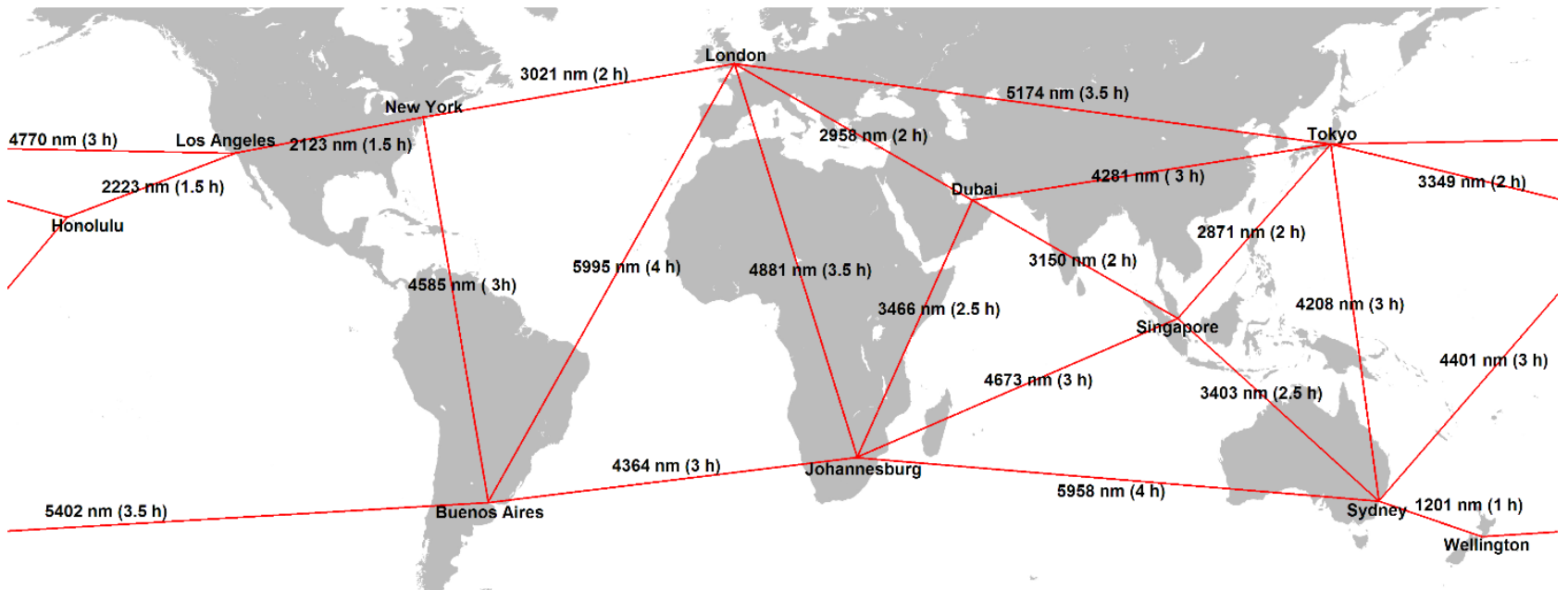

Figure 3. Approximate range and times at 1500 knots between key intercontinental airports

still produce high values of the Cook's $D$ statistic (>2.0), indicating high leverage on the subject formula and a high standardized residual. This is likely to be because the aircraft, while useful for this analysis, were optimized for different missions and involved different technologies.

\section{Optimising Criteria for Sizing}

The three main criteria for the initial size of a new supersonic transport aircraft are range, speed and the number of passengers. Range was explored as shown on the intercontinental network map shown in Figure 3. There are very long routes in current use, in excess of
$8500 \mathrm{~nm}$ and taking around 16 to 17 hours, such as Sydney to London. Some of these, like Australia to South America are still relatively low volume. Hence, the range decision needed to be a trade-off that includes time-offlight.

Noting the aim of commercial viability, the possible speed of a supersonic transport was kept to realistically achievable values of Mach 3 and 1,500 knots, because:

(1) this is high enough to drop travel times substantially to a third of current values; 
(2) is still where the fuel consumption of conventional turbojets is better than an ideal ramjet, which are as yet unproven commercially [11, p. 767]; and

(3) is still within the historical cases on which the regression is based.

With speed set at 1,500 knots and Mach Number at 3, range then becomes an issue of the tolerance for stopovers, versus the challenge of a high fuel consumption (at such speed) and the difficulties of accommodating a high fuel fraction of overall take-off weight within a necessarily slender supersonic body. Passengers travelling London to Sydney are primarily likely to want to spend less time travelling and the only current option is taking out stop-overs. Consider the Sydney to Los Angeles route, which currently takes about 14 hours and is direct. At 1,500 knots a supersonic aircraft can achieve this in three hours to Honolulu and 1.5 hours to Los Angeles, which even with an hour stop-over, would still reduce the journey to between a half and a third. Similarly, London to Sydney can be achieved in three short flights of around two hours each, or an overall time of about nine hours. Hence the trade-off range suggested is $6,000 \mathrm{~nm}$ with the travel times and possible supersonic network nodes as shown in Figure 3. an expectation that this may need to be as low as 150 passengers.

\section{Optimizing Initial Size Solution}

The eight dimensional input space of the formulae from the historical regression needed more than the three main criteria to converge on a sensible solution. Initial attempts sought to go underground with a negative ceiling, or would drive take-off weight to very high proportions relative to the empty weight, which from conventional methods [5] was known to be unrealistic. So the following additional criteria were imposed:

(1) Service ceiling was limited to between 20,000 and 50,000 feet, where the challenges of engine intakes, air traffic control and passenger safety are well-known.

(2) The ratio of take-off weight to empty weight was constrained to 2.5 , which is realistic with four of the historical aircraft achieving this ratio or better.

(3) The lift-to-drag ratio was allowed to go up to 3.5 , which is outside any of the historical designs (i.e., > 3.18), based in part on the modern ability for computational fluid dynamics to drive superior aerodynamic conformal

Table 3. EVA inputs and output constraints with initial settings and final solution

\begin{tabular}{lllll}
\hline \hline \multicolumn{4}{c}{ EVA Inputs } & \\
\hline \multirow{2}{*}{ Factor } & $\begin{array}{l}\text { Distribution } \\
\text { Type }\end{array}$ & $\begin{array}{l}\text { Initial Value } \\
\text { (mid or set) }\end{array}$ & $\begin{array}{l}\text { Standard } \\
\text { Deviation }\end{array}$ & $\begin{array}{l}\text { Optimised } \\
\text { Solution }\end{array}$ \\
\hline Empty Weight (lb) & Normal & 148,667 & 1,000 & $223,960.4$ \\
MTOW (lb) & Normal & 340,305 & 1,000 & 518,771 \\
Length (ft) & Normal & 200 & 3 & 200 \\
Wingspan (ft) & Normal & 74.415 & 3 & 120.314 \\
Height (ft) & Normal & 29.5 & 1 & 42.516 \\
Wing area (sq ft) & Normal & $3,223.88$ & 9 & $6,568.05$ \\
Wing loading (lb / sq ft) & Normal & 105.5 & 0.6 & 56.614 \\
Lift to drag ratio & Normal & 2.14 & 0.2 & 2.715 \\
\hline \hline
\end{tabular}

\begin{tabular}{lll}
\hline \multicolumn{3}{c}{ EVA Output Constraints } \\
\hline Name & LSL & USL \\
\hline Maximum Speed (knots) & 1,300 & 1,600 \\
\hline Maximum Mach No & 2 & 3 \\
\hline Service Ceiling (ft) & 20,000 & 50,000 \\
\hline Range (nm) & 6,000 & 7,000 \\
\hline Ratio MTOW to Empty Weight & 1 & 2.5 \\
\hline Lift to Drag Ratio & 2 & 3.5 \\
\hline
\end{tabular}

Note: LSL \& USL are lower \& upper specification limits

The subsonic Airbus 380 is 238 feet long and seats comfortably about 484 passengers. The Concorde was 202 feet long and carried 128 passengers and the Tu-144 was 215 feet long and carried 140 passengers. Both of these supersonic historical aircraft targeted the high-end executive traveller and thus perhaps more passengers could be fitted if similar space constraints are applied as current short-time economy flights. The slenderness requirements of fuselages in supersonic flight is going to be a design challenge. Rather than try to set a number of passengers, this conceptual sizing used aircraft length as the substitute, setting a minimum length of 200 feet with the target of this holding up to 200 passengers, but with as robust design [7, pp. 205-212]. The input variations and output specification limits for the EVA and robust design optimization are in Table 3 , where the initial values to begin the EVA were the mid-range values for the 14 historical aircraft, except for length, which was set to 200 feet as discussed earlier. The input variations were set around estimates of initial design limits, such as a 1,000 pounds standard deviation on empty weight, or three feet in length; however, these estimates should at some stage be confirmed with a fully representative design team.

The solution was optimized using the criteria of minimizing the observed defects per million in each of 1,000 Monte Carlo simulations, where all six outputs 
were weighted equally. The solution compares to that outlined earlier [4] as lighter (518,771 c.f. $666,665 \mathrm{lbs})$ and smaller in wing area (6,568 c.f. $8,162 \mathrm{sq} \mathrm{ft})$, however that solution was based on 305 passengers vice $150-200$ passengers, was for a range of 5,000 nm rather than 6,000 $\mathrm{nm}$, and included the greater fidelity of a dedicated aircraft optimization computer. The aircraft shape is still to be determined, but examples of what these dimensions would look like are in Figure 4.

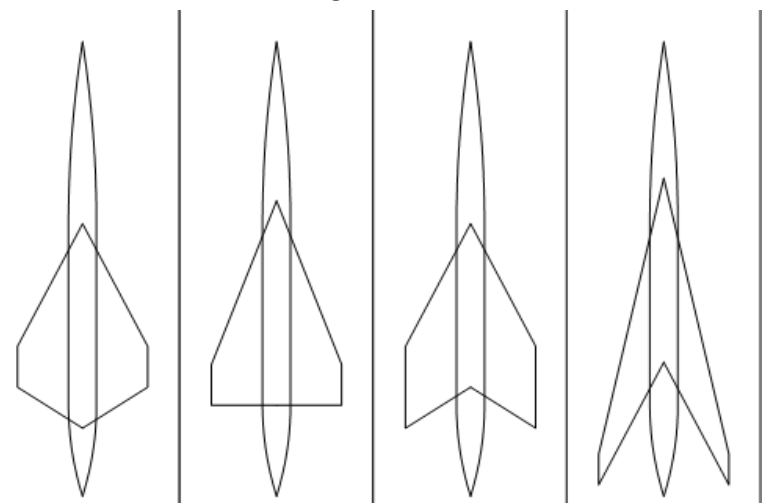

Figure 4. Example aircraft planforms to achieve the solution dimensions in Table 3

The achieved output values are shown probabilistically with their specification limits overlaid in Figures 5-6. The ratios of $M T O W$ to empty weight and lift-to-drag are not shown, as these were both at values well within the specified limits, with means and standard deviations of $\{2.316,0.0118\}$ and $\{2.717,0.198\}$ respectively; and as such, neither had any observed exceedances. The lift-to-drag ratio was reassuringly within the historical solution space (i.e., < 3.18) despite being allowed to extrapolate if necessary up to 3.5 in value.
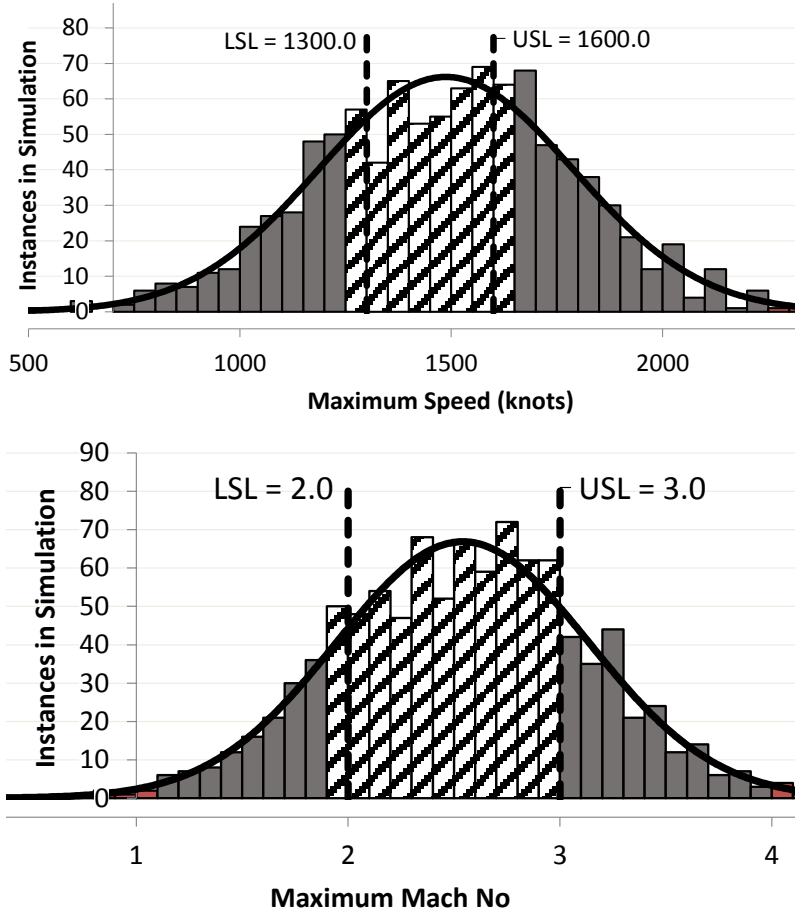

Figure 5. Maximum Speed and Mach No achieved relative to the limits set (hatched inside limits, grey outside)
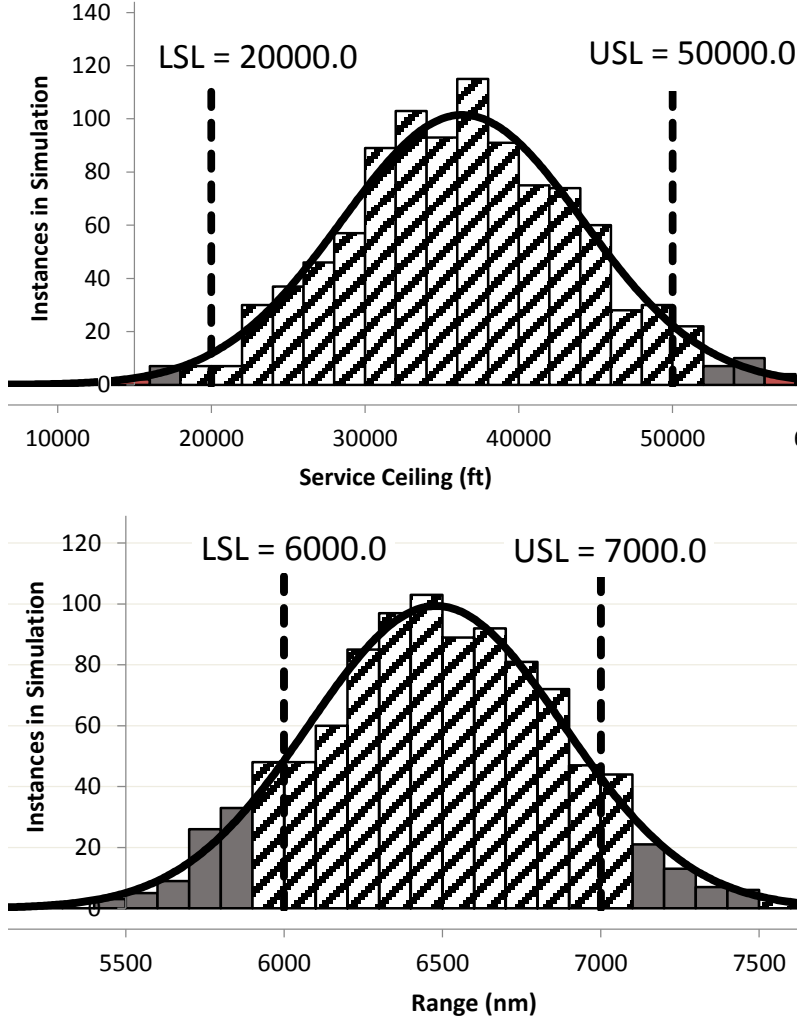

Figure 6. Service Ceiling and Range achieved relative to the limits set (hatched inside limits, grey outside).

\section{Sensitivity Analysis for Robust Design}

One of the benefits of robust design techniques in DFSS is sensitivity analysis, where the sensitivity of probabilistic relationships to input variations can be determined so as to inform subsequent design iterations where these design margins or tolerances are likely to be most critical [7, pp. 269-274]. Such sensitivity analysis in the optimization of aircraft conceptual designs is similar to recent dissertation research [15] that had critical outputs of range, landing distance and specific range (nautical mile per pound). For the supersonic aircraft regression model in this study there are 32 combinations of sensitivity to consider, based on eight inputs and four outputs. The major concern for the next sizing iteration would be the effect of a shift in any input mean and this is shown in Table 4.

Clearly the greatest sensitivity to input changes is the Service Ceiling followed by the Range, while the most critical of inputs is the wingspan and then MTOW, wing area and wing loading. The next iteration of the conceptual design can use this information to prioritize tracking of these key design measures. 
Table 4. Sensitivity Analysis results showing effect of absolute change in each output from a +0.5 sigma and a -0.5 sigma shift in the mean of the input.

\begin{tabular}{|c|c|c|c|c|c|}
\hline \multirow[b]{2}{*}{ Inputs } & \multirow[b]{2}{*}{$\begin{array}{l}0.5 \text { sigma } \\
\text { shift }\end{array}$} & \multicolumn{4}{|c|}{ Outputs } \\
\hline & & $\begin{array}{l}\text { Maximum Speed } \\
\text { (knots) }\end{array}$ & $\begin{array}{c}\text { Maximum Mach } \\
\text { No }\end{array}$ & $\begin{array}{c}\text { Service Ceiling } \\
\text { (ft) }\end{array}$ & Range (nm) \\
\hline Empty Weight (lb) & $500 \mathrm{lb}$ & $1.34 \%$ & $3.12 \%$ & $32.00 \%$ & $9.50 \%$ \\
\hline MTOW (lb) & $500 \mathrm{lb}$ & $5.71 \%$ & $11.75 \%$ & $27.99 \%$ & $13.58 \%$ \\
\hline Length (ft) & $1.5 \mathrm{ft}$ & $4.26 \%$ & $7.82 \%$ & $13.56 \%$ & $10.56 \%$ \\
\hline Wingspan (ft) & $1.5 \mathrm{ft}$ & $8.09 \%$ & $18.13 \%$ & $73.81 \%$ & $54.59 \%$ \\
\hline Height (ft) & $0.5 \mathrm{ft}$ & $2.67 \%$ & $4.55 \%$ & $61.18 \%$ & $7.36 \%$ \\
\hline Wing area $(\mathrm{sq} \mathrm{ft})$ & $4.5 \mathrm{sq} \mathrm{ft}$ & $1.33 \%$ & $2.75 \%$ & $38.53 \%$ & $18.35 \%$ \\
\hline $\begin{array}{l}\text { Wing loading (lb / sq } \\
\mathrm{ft} \text { ) }\end{array}$ & $0.3 \mathrm{lb} / \mathrm{sqft}$ & $1.89 \%$ & $3.14 \%$ & $40.75 \%$ & $18.65 \%$ \\
\hline Lift to drag ratio & 0.1 & $1.38 \%$ & $4.23 \%$ & $7.11 \%$ & $1.52 \%$ \\
\hline
\end{tabular}

significant (>20\%) shift in quality for design goals moderate (10-20\%) shift in quality for design goals insignificant $(<10 \%)$ shift in quality for design goals

\section{Study Limitations and Further Design}

There are noteworthy limitations in this Study, typical of early conceptual sizing of a platform based on historical data. For example, all relationships suffered from poor multi-collinearity. Primarily, there is a limited data set of prior designs to inform the historical analysis, while that set of aircraft designs are each somewhat unique and therefore, to some extent, not a readily comparable family. Also these designs are increasingly dated since supersonic transport design has commercially stagnated. Yet, the only alternative is to design without reference to previous attempts. A true validation check of the model is not possible at this time due to the lack of new supersonic aircraft designs being ready for flight testing.

The optimization was based on estimates of the range and travel timings for a future aircraft network without any passenger survey or traffic density analysis and predictive business modelling. Also, the EVA was based on estimated input variations that would need confirming with a team of design specialists before the next conceptual design iteration. Finally, this research has not considered regulatory challenges such as sonic boom issues over land. Ideally the subsequent design iteration should seek a further multidisciplinary optimization that incorporates commercial cost relationships, aircraft aeroacoustic modelling and passenger preference relationships, as well as contemporary propulsive, structural and aerodynamic design factors that go beyond simple weight fractions. These next iterations of the design would expand eventually to a high-dimensional, computationally-expensive and 'black box' problem [12]. In pursuing increased fidelity of optimization, the authors favour following the DFSS strategies of screening and focusing on the most sensitive factors, as well as examining the merit of breaking the global range and endurance sectors (Figure 3) into mission modules for the optimization, as was outlined recently for design of an unmanned aerial vehicle [16, pp. 199-202]. There is potential to use some of the new adaptable parametric sizing methods proposed in dissertation research [17] and to continue conceptual design optimization with uncertainties [18] — wherever possible still using commercially available software [13].

\section{Conclusions}

This Study has analyzed historical supersonic transport aircraft designs to determine probabilistic relationships between key design input factors and the responses of maximum speed, maximum Mach Number, service ceiling and range. This study optimizes with a method between the two extremes of the NASA optimization techniques [4] and the Raymer textbook method [5]. Only the equation for service ceiling was statistically weak in significance and had to be persisted with for the completeness of the solution space. The analysis has then used standard software packages and DFSS techniques, which are available to post-graduate students, in order to optimize around an initial concept size using robust design techniques. A simple consideration of a possible intercontinental airport network set a realistic target range of $6,000 \mathrm{~nm}$ and travel times of about one-third of current values, based on a speed of 1,500 knots and a Mach Number of 3.0. Aircraft length was used to approximate a number of passengers of between 150 and 200 .

The approximate solution is a supersonic aircraft with an empty weight of $224,000 \mathrm{lbs}$, a $M T O W$ of 2.3 times that at 519,000 lbs, a length and height of $200 \mathrm{ft}$ and $42.5 \mathrm{ft}$ respectively, a wingspan of $120 \mathrm{ft}$, a wing area of 6,570 sq ft and a wing loading and lift-to-drag ratio of $56.6 \mathrm{lb} / \mathrm{sq} \mathrm{ft}$ and 2.7 respectively. The analysis showed this conception to be reasonably robust to input variations at this design solution, with the most sensitive output to input changes being service ceiling, especially to changes in wingspan. This work is the first supersonic transport aircraft sizing to use commercially-available Excel addon software and standard DFSS analysis techniques, notably for the sensitivity analyses to guide the next design iteration. 
The authors are interested in furthering the use of the DFSS methods used here and in working with an enhanced aircraft design team on the next conceptual design iteration for a commercially viable supersonic transport aircraft. In particular, to examine how the sensitivity results best influence the next design iteration. There is potential to use some of the new adaptable parametric sizing methods and to continue conceptual design optimization with uncertainties - wherever possible still using commercially available software. Given the age of the designs used in this analysis, coupled with advances in technology and design skills, the recommended supersonic transport aircraft design should be much more assured than its predecessors.

\section{References}

1. A. Giordani, Could an airliner that flies anywhere in under three hours be in service by 2030?, BBC newspaper [online] (15th Sept. 2015)

2. J. Anderson and R. Passman, X-15: The World's fastest rocket plane and the pilots who ushered in the Space Age (Zenith Press, 2014).

3. J. Sobieszczanski-Sobieski and R. T. Haftka, J. Struct. Opt. 14, 1-23 (1997).

4. S. N. Patnaik, J. D. Guptill, D. A. Hopkins and T. M. Lavelle, J. of Aircraft 35, 839-850 (1998).

5. D. P. Raymer, Aircraft design: a conceptual approach 5th ed. (AIAA, 2012).

6. H. Xue, H. Khawaja and M. Moatamedi, AIP Conf. Proc. 1637 1202-1210, (2014).
7. L. A. Reagan and M. J. Kiemele, Design for six sigma: the tool guide for practitioners (Air Academy Associates, 2008).

8. P. N. Koch, R. J. Yang and L. Gu, J. Struct. Multidisc. Opt. 26, 235-248 (2004)

9. I. Ferreira, J. A. Cabral, P. Saraiva and M. C. Oliveira, J. Struct. Multidisc. Opt. 49, 501-521 (2014).

10. K. F. Joiner, M. Kiemele and M. McAuliffe, ITEA J. 37, 141-152 (2016)

11. J. D. Anderson, Introduction to Flight 8th ed. (McGraw-Hill, 2016).

12. S. Shan and G. G. Wang, J. Struct. Multidisc. Opt. 41, 219-241 (2010).

13.J. Watson, A high-fidelity approach to conceptual design, $\mathrm{PhD}$ dissertation ProQuest Dissertations Publishing ISBN: 9781339847092 (2016).

14 A. Lenz, Simple uncertainty propagation for early design phase aircraft sizing, $\mathrm{PhD}$ dissertation ProQuest Dissertations Publishing (2010).

15. M. J. Daskilewicz, B. J. German, T. T. Takahashni, S. Donovan and A. Shajanian, J. Struct. Multidisc. Opt. 44, 831-846 (2011).

16. P. K. Lewis, V. R. Murray and C. Mattson, J. Struct. Multidisc. Opt. 43, 191-204 (2011).

17. G. Coleman, Aircraft conceptual design - an adaptable parametric sizing methodology $\mathrm{PhD}$ dissertation ProQuest Dissertations Publishing ISBN: 9781124055336 (2010).

18.D. Neufeld, Multidisciplinary aircraft conceptual design optimization considering fidelity uncertainties, PhD dissertation, ProQuest Dissertations Publishing, ISBN: 9780494714034 (2010) 